\title{
Parodi Sebagai Strategi Kreatif Iklan di Indonesia (Studi Kasus Iklan Ovo X Grab Versi Rhoma Irama)
}

\author{
Ahmad Fauzi, Wulan Purnama Sari \\ Ahmad.915150080@stu.untar.ac.id,wulanp@untar.ac.id
}

Fakultas Ilmu Komunikasi, Universitas Tarumanagara

\begin{abstract}
Today many ads use parodies. Parody are an imitations of a form or type of story used to quip or to create a humorous effect. One of them is the OVO x GRAB version of Rhoma Irama ad. Where adverts are online transportation services, this Grab has a unique concept while tickling. It was like the scene of the legendary film Rhoma Irama. The problem faced is how the formulation of the parody advertising strategy for the OVOX GRAB advertisement version of Rhoma Irama. In this study qualitative methods were used. Qualitative research aims to understand the phenomenon of what is experienced by the subject of research such as behavior, perception, motivation, action and others holistically and by means of descriptions in the form of words and languages, in a specific natural context and by utilizing various methods scientific. The results of the study show that the creative concept of parody approach is an excellent advertising technique to achieve various marketing communication goals if implemented properly and relevant to the product. This is evidenced by the consistency of the OVO $x$ GRAB Advertisement Version of Rhoma Irama using a creative concept so that its products are known to the wider community. In formulating creative concepts, the creative team Ambilhati agency conducted an ad strategy formulation in three stages, namely collecting and preparing all marketing information (consumer information, products, competitors), processing the information obtained to determine the positioning and purpose of advertising and presentation in front of client to get an agreement or agreement before the execution process.
\end{abstract}

Keywords: Parody, Creative Strategy, Advertising, OVO, GRAB.

\begin{abstract}
Abstrak
Saat ini banyak iklan yang menggunakan parodi. Parodi adalah suatu peniruan bentuk atau jenis cerita yang digunakan untuk menyindir atau untuk menciptakan efek humor dan gelak tawa. Salah satunya adalah iklan OVO x GRAB Versi Rhoma Irama. Iklan layanan transportasi online Grab ini punya konsep yang unik sekaligus menggelitik. Isinya bak adegan film legendaris Rhoma Irama. Permasalahan yang dihadapi adalah bagaimana formulasi strategi iklan parodi atas iklan OVO X GRAB versi Rhoma Irama. Penelitian ini menggunakan metode penelitian kualitatif. Penelitian kualitatif bertujuan untuk memahami fenomena tentang apa yang dialami oleh subjek penelitian misalnya perilaku, persepsi, motivasi, tindakan dan lain-lain seara holistik dan dengan cara deskripsi dalam bentuk katakata da bahasa, pada suatu konteks khusus yang alamiah dan dengan memanfaatkan berbagai metode ilmiah. Hasil penelitian menunjukkan bahwa konsep kreatif yang memadukan unsur pendekatan parodi adalah suatu teknik periklanan yang sangat menarik dan dapat diterapkan dengan baik dalam suatu produk. Hal ini menjadi bukti adanya keseriusan Iklan OVO x GRAB versi Rhoma Irama dalam menggaet khalayak ramai atau konsumen dengan menggunakan konsep kreatif yang baik, sehingga produk-produknya dikenal publik atau masyarakat luas. Dalam merumuskan konsep kreatif, tim kreatif Ambilhati agency melakukan formulasi strategi iklan dalam tiga tahapan yaitu dengan cara mengumpulkan dan mempersiapkan segala informasi pemasaran yang dibutuhkan dan mampu mengolah informasi yang didapat guna penetapan suatu positioning secara tepat dan penetapan tujuan
\end{abstract}


iklan serta presentasi produk di hadapan klien guna mendapatkan persetujuan sebelum proses eksekusi dilakukan.

Kata Kunci : Parodi, Strategi Kreatif, Iklan OVO, GRAB.

\section{Pendahuluan}

Iklan merupakan salah satu bentuk promosi yang paling dikenal dan paling banyak dibahas orang saat ini, hal ini dikarenakan daya jangkauannya yang luas dan daya tariknya yang tinggi. Proses pembuatan iklan oleh perusahaan periklanan membutuhkan kejelian dan kreativitas agar iklan yang dihasilkan sesuai dengan karakter produk sesuai keinginan pengiklan dan yang terpenting mencapai tujuan guna mempersuasi penyimaknya hingga emosinya terikat dan tertarik untuk membeli. Penciptaan iklim kreatif menjadi penting untuk menjaga kreativitas para pembuat iklan. Saat ini banyak iklan yang menggunakan parodi. Parodi adalah suatu bentuk peniruan dari sebuah jenis cerita yang digunakan untuk menyindir atau untuk menciptakan efek humor dan gelak tawa. Salah satunya adalah iklan OVO x GRAB Versi Rhoma Irama. Iklan ini memiliki konsep yang unik menggelitik. Berdurasi sekitar 1 menit, iklan ini menampilkan salah satu fitur pembayaran jasa Grab, yakni OVO, tapi dengan menampilkan potongan adegan yang terinspirasi oleh film legendaris Berkelana. Iklan ini terbilang menarik karena memarodikan adegan film Berkelana tetapi berisikan promosi fitur OVO, ditambahi adegan-adegan unik lainnya yang kocak dan menghibur.

Berdasarkan hal tersebut, maka penulis memfokuskan permasalahannya pada bagaimana formulasi strategi iklan parody atas iklan OVO X GRAB versi Rhoma Irama?

\section{Metode Penelitian}

Penelitian ini menggunakan metode kualitatif yang bersifat deskriptif, artinya penelitian ini harus mampu menggambarkan bagaimana temuan hasil penelitian untuk menjawab permasalahan yang telah dijelaskan di awal sehingga bisa direalisasikan dengan mudah dan gampang (Herdiansyah, 2010). Data penelitian ini diperoleh dari suatu proses wawancara mendalam dengan beberapa narasumber, observasi atau pengamatan, dan tinjauan literatur atau stuudi pustaka. Subjek dalam penelitian ini adalah informan kunci, yaitu Ibu Khania Giana selaku Sr. Copywriter dan Tegar Yudhanataru selaku Sr. Art Director dari kantor Ambilhati Agency. Subyek penelitian dalam penelitian ini adalah pembuat iklan OVO x GRAB versi Rhoma Irama, sedangkan objek penelitiannya adalah Iklan OVO x GRAB Versi Rhoma Irama. Teknik pengumpulan data dalam penelitian ini adalah wawancara, pengumpulan dokumen, dan lain-lain. Analisis data dimulai dengan menelaah seluruh data yang ada, yang berasal dari berbagai sumber yaitu dari wawancara, dokumen pribadi, dokumen resmi, gambar, foto dan sebagainya. Data-data dari temuan penelitian kualitatif itu akan dinyatakan sah bilamana tidak ada perbedaan antara yang dilaporkan oleh peneliti dengan yang sesungguhnya terjadi pada objek penelitian yang diteliti. 
Fauzi Ahmad, Wulan Purnama Sari: Parodi Sebagai Strategi Kreatif Iklan di Indonesia (Studi Kasus Iklan Ovo X Grab Versi Rhoma Irama

\section{Hasil Penelitian}

OVO x GRAB melakukan kerjasama dibidang kemitraan strategis (strategic partnership). Kemitraan strategis memungkinkan pengguna OVO melakukan top up saldo langsung melalui mitra pengemudi Grab. OVO mengumumkan berkolaborasi dengan perusahaan Grab, mitra dalam teknologi dan inovasi adalah suatu titik awal kemitraan bisnis ini berjalan. Setelah sebelumnya OVO wallet tersedia diaplikasi Grab, OVO wallet saat ini sudah dapat digunakan sebagai alat pembayaran untuk berbagai layanan transportasi Grab dan pengiriman GrabFood yaitu 60 juta pengguna. Baik Grab dan OVO pada dasarnya memiliki misi yang sama dalam mewujudkan inklusi keuangan dan digital, dan pada saat ini, perusahaan ini bermitra dan berkolaborasi ke tahap lebih jauh menuju suatu relung bisnis yang menjanjikan.

Strategic partnership dengan OVO adalah suatu bagian dari open ecosystem yang dilakukan untuk menyentuh 60 juta pengguna smartphone di Indonesia termasuk para pengguna Grab yang tersebar di 135 kota. Grab sepenuhnya bakal menyerahkan mekanisme transaksi non-tunai kepada OVO. Dengan adanya strategic partnership, seluruh kebutuhan pembayaran digital pelanggan Grab bisa terlaksana dan terealisasi secara cepat, tidak hanya pembayaran transportasi online, tetapi juga untuk pembayaran pesan-antar makanan alias GrabFood, yang sebelumnya tidak bisa dilakukan oleh GrabPay karena suatu kendala teknis yang tidak diketahui permasalahannya.

Iklan OVO x GRAB ditayangkan awal Juni 2018. Media yang digunakan adalah televisi dan media sosial (medsos). Iklan OVO x GRAB berdurasi sekitar 1 (satu) menit ini menampilkan salah satu fitur pembayaran jasa Grab, yakni OVO. Guna mempromosi suatu produk, tentu saja tidak hanya dengan promosi-promosi yang sudah dilakukan oleh perusahaan on demand platform lainnya. Tentu saja penggunaan iklan sebagai media promosi menjadi pilihan utama bagi perusahaan. Periklanan merupakan suatu alat penciptaan pesan dan mengirimkannya kepada orang lain dengan harapan orang tersebut bereaksi dengan cara tertentu (Sandra Morianty \& Nancy Mitchell, 2011).

Banyaknya iklan yang muncul diberbagai media, tentu saja membawa berbagai macam pesan yang ingin disampaikan oleh pengiklan kepada targetnya. Namun banyaknya iklan yang begitu-begitu saja tentu membuat sebuah iklan kurang obyektif.

Mengacu pada teori strategi iklan, di mana strategi iklan menjadi hal yang sangat penting dalam mengeksekusi sebuah iklan yang kreatif, karena pemilihan media yang tepat juga dapat mendorong efektivitas sebuah iklan dalam menyampaikan pesan ke khalayak. Dalam mengiklankan sesuatu, diperlukan media yang menjadi alat atau saluran yang digunakan dalam menyampaikan pesan. Media ini terbagi menjadi dua yaitu: media digital dan media cetak. (Ardianto, 2004)

Hasil dari penelitian ini adalah inti keseluruhan isi penelitian yang dilakukan peneliti, di mana hal inilah yang sebenarnya menjadi fokus dari permasalahan yang diangkat oleh peneliti. Dalam hal ini, peneliti mengolah data yang diperoleh melalui sarana wawancara dengan Ibu Khania Giana selaku Sr. Copywriter dan Tegar Yudhanataru selaku Sr. Art Director dari kantor Ambilhati Agency. Data ini digunakan untuk mencari tujuan penelitian guna mengetahui secara mendalam mengenai formulasi strategi iklan parodi pada iklan OVO X GRAB versi Rhoma Irama. 
Iklan OVO x GRAB diperoduksi oleh Dimas Dyajadiningrat melalui Ambilhati Agency. Mengusung tema yang unik dalam konsep iklan sebuah produk $e$-Money. Emoney adalah suatu alat pembayaran atau transaksi yang menggunakan media elektronik, yaitu jaringan computer dan juga internet. E-money disebut juga merupakan electronic cash, digital money, digital cash, electronic currency ataupun digital ataupun digital currency. E-money sangat aman untuk digunakan dalam sautu transaksi apapun. Bahkan ilmu kriptografi menyatakan bahwa uang elektronik itu sangat sulit untuk diretas atau dibajak.

Berdasarkan iklan OVO x GRAB versi Rhoma Irama, dengan pendekatan teori strategi iklan, penulis berpendapat bahwa strategi iklan memegang peranan yang sangat vital dalam penentuan keberhasilan iklan suatu perusahaan. Strategi ini pada dasarnya mampu membangun merek, dan strategi ini mampu menjaga agar periklanan dan elemen pemasaran berada dalam jalur yang tepat serta mampu membangun kepribadian merek dengan jelas dan konsisten. Strategi ini mampu mewakili jiwa sebuah merek dan menjadi suatu elemen penting bagi keberhasilan suatu iklan produk.

Penelitian tentang "Parodi Sebagai Strategi Kreatif Iklan di Indonesia (Studi Kasus Iklan OVO x GRAB Versi Rhoma Irama)" ini, peneliti melakukan interview dengan narasumber andal di agency periklanan "Ambilhati”, yaitu Kania Giana selaku Sr. Copywriter dan Tegar Yudhanaaru selaku Sr. Art Director dalam pembuatan iklan tersebut. Peneliti melakukan wawancara di Kantor Ambilhati Agency yang beralamat di Jalan Jembatan Tengah No. 2, RT.10/RW.5, Pulo, Kebayoran Baru, Kota Jakarta Selatan pada tanggal 26 April 2019. Narasumber ini dianggap kredibel, mengingat ia adalah orang yang berkompeten dan orang yang memiliki tanggungjawab penuh dalam hal perancangan konsep kreatif hingga pelaksanaan iklan OVO x GRAB versi Rhoma Irama.

Menurut Khania Giana, dan Tegar Yudhanataru, formulasi strategi iklan parodi dari iklan OVO X GRAB versi Rhoma Irama adalah :

"Sebenarnya karena trend, dan ini memang keinginan klien, klien pingin yang lucu dan pakai message. Terkait dengan iklan OVO x GRAB versi Rhoma Irama yang mengedepankan konsep di tahun 1980-an. Pada persepsi ini, jelas bahwa iklan merupakan suatu media komunikasi visual dengan menyampaikan pesan verbal visual dari produsen kepada calon konsumen serta memiliki strategi visual handal guna menghadapi persaingan yang kompetitif dengan produk sejenis oleh pihak pesaing. Strategi visual itu biasanya menyangkut beberapa hal, diantaranya adalah iklan harus menyampaikan pesan dengan makna tertentu melalui bahasa gambar mempunyai efek vocal point dan memiliki daya tarik atau daya pikat untuk menarik hati audiens, dan menimbulkan kejutan pada target khalayak sasaran secara keseluruhan."

Ini artinya bahwa ada perubahan trend iklan yang didorong oleh jenis-jenis iklan yang terbit di media internet, seperti iklan video yang sarat dengan bahasa gambar. Iklan seperti ini akan "melegakan" perasaan akan lebih berkesan di tiap pemirsa iklan. Hal inilah yang dapat memberikan efek menarik pada produk atau jasa yang ditawarkan oleh perusahaan pemasang iklan t saat ini.

Mengacu mengenai teori parodi, seperti dijelaskan M. Alwi Dahlan (2008) bahwa parodi menjadi perlawanan dan pembeda antara 2 teks. Parodi juga bisa dipandang sebagai sebuah seni; baik lakon ataupun tulisan menggunakan tema kritik 
dengan canda menertawakan diri sendiri. Hal yang bisa dijadikan objek parodi adalah gerakan, artis secara spesifik, literatur, komentar editorial, karya individual, dan lain-lain. Kini, parodi masuk hampir di semua aspek media sebagai budaya popular kontemporer. Parodi membuka peluang seluas-luasnya bagi interpretasi masing-masing pihak

Berdasarkan uraian tersebut di atas penulis berpendapat bahwa parodi dalam Iklan OVO x GRAB versi Rhoma Irama adalah wacana yang mempertanyakan kembali suatu subjek pencipta sebagai sumber makna dan arti. Agency menyiratkan satu upaya dengan melalui berdialog mengenai produk OVO ketika menggunakan jasa GRAB dan iklan ini mampu membangun dedikasi diri dan merujuk orang dengan seperangkat kode-kode sebagai satu upaya ideologis (yaitu mampu mempengaruhi pikiran, selera, perasaan serta tindakan sosial seseorang atau kelompok), serta adanya ide suatu produk OVO yang memang merupakan suatu trend pembayaran masa kini. Di dalam parodi terdapat sebuah ruang kritik (saran membangun) guna mengungkapkan satu ketidakpuasan atau bisa juga sekadar ungkapan rasa humor belaka sehingga mampu menimbulkan gelak tawa bagi audiens yang melihatnya. Untuk itu, adanya kritik, sindiran, kecaman, plesetan, olok-olok, main-main, seringkali dijadikan sebagai titik awal dari suatu pesan parody, dan ini tentunya merupakan salah satu strategi visual dan parodi yang juga merupakan relasi visual dan makna serta arti dari keduanya baik melalui teks atau gambar yang menghasilkan sebuah komposisi dan makna baru.

Menarik untuk dibahas bahwa parodi mampu membangun cakrawala sense of humor di tengah masyarakat. Di mana dunia akan tampak kaku tanpa kehadiran parodi. Apalagi parodi selalu membangun dan mampu mengkomunikasikan pesan secara baik dan mampu meningkatkan kepercayaan diri serta mampu memikirkan situasi di mana pesan itu disampaikan (Sumbo Tinarbuko, 2006).

Hal tak terkalah penting, dalam merumuskan suatu konsep kreatif, tim kreatif agency Ambilhati akan melakukan tiga tahapan yakni mengumpulkan suatu informasi terkait produk yang mau diiklankan competitor atau pesaing dan kemudian mengolah pihak agency akan menjadikan informasi tersebut menjadi ide kreatif yang baik. Dalam pem-positioning produk, tim kreatif akan membuat alur storyboard, script dan stillomatic untuk bisa dipresentasikan di hadapan klien sebelum dieksekusi.

Penulis berpendapat bahwa seorang copywriter harus mampu menciptakan script iklan yang baik dan menarik dan tentunya alur cerita yang dibuatnya nyambung dengan makna iklan yang disampaikan, dan tentunya juga harus mampu mengatasi masalah pesan iklan yang sesuai dengan masalah persepsi dari target market sebenarnya. Salah satunya adalah dengan mengembangkan suatu format naskah iklan atau konsep yang menarik, mudah diingat di tengah kekacauan iklan (pada saat iklan mendapat rating rendah atau bahkan mendapat rating tinggi di tengah-tengah publik).

Terkait dengan teori kreativitas (Durianto, dkk, 2003), tentunya ada yang harus diperhatikan dalam merumuskan kreativitas iklan dalam hubungannya dengan iklan OVO x GRAB versi Rhoma Irama, diantaranya adalah :

\section{Directed Creativity}

Kreatifitas harus dibuat sesuai what to say. What to say yang dimaksud adalah ungkapan inti pesan dari iklan OVO x GRAB sampai ke sasaran dan dalam hal ini sasaran mampu memahami, memaknai inti pesan yang disampaikan. Inti 
pesan dari iklan ini adalah "PAKE OVO AJA". Iklan ini mengajak khalayaknya untuk menggunakan OVO sebagai sarana pembayaran.

2. Brand Name Exposure

Untuk meendapatkan brand awareness pada iklan OVO x GRAB, pengiklan ini harus mampu menunjukkan kelebihan dari OVO, sehingga khalayak sasaran bisa membandingkannya dari produk competitor, sehingga mengingatkan sasaran akan selalu menggunakan alat pembayaran elektronik dengan menggunakan OVO.

3. Positive Uniqueness

Positive uniqueness di sini maksudnya adalah iklan OVO x GRAB tersebut memiliki keunikan, kekhususan dan bahkan mampu membedakannya dengan produk competitor.

4. Selectivity

Maksud dari selectivity dalam iklan OVO x GRAB adalah sasaran harus mampu memilih dari pilihan alat pembayaran yang sesuai diantara alat pembayaran lain dan tentunya alat pembayaran tersebut bisa memenuhi selera sasaran, yang dalam hal ini adalah OVO.

Dalam hubungannya dengan iklan parody OVO x GRAB, penulis berpendapat bahwa strategi parodi dilihat dari sisi visual gambar dan dialog kata. Contoh kata berkelana menjadi parodi iklan tentu hal ini menjadi menarik. Sebab, iklan berdurasi sekitar 1 menit ini menampilkan salah satu fitur pembayaran jasa Grab, yakni OVO, tapi dengan menampilkan potongan adegan yang diadaptasi dari film Berkelana.

Hubungannya dengan teori kreativitas, di mana adanya tindakan kreatif muncul atas keseluruhan kepribadian dalam interaksinya dengan lingkungannya, khususnya dalam iklan OVO vs GRAB versi Rhoma Irama ini. Kreator atau pembuat iklan harus mampu mengikuti selera pasar agar tidak kalah bersaing dengan iklan lain yang sejenis, seperti iklan competitor. Sebab, terkadang kreativitas yang berlebihan justru akan ditolak pasar atau dengan kata lain tidak mengenai sasaran. Kreativitas memang perlu untuk dikembangkan tetapi ide, konsep, serta efektivitas penyampaian pesan dalam iklan yang utama menjadi hal yang utama. Untuk itulah peran advertising agency atau agen periklanan dibutuhkan saat ini. Konsep iklan yang tepat dan menarik perhatian, tentunya menjadi harapan akan pengembangan produkproduk yang dikenal masyarakat secara luas, sehingga masyarakat mau membeli produk yang diiklankan atau setidaknya mengingat produk tersebut.

\section{Simpulan}

Strategi iklan parody pada iklan OVO X GRAB versi Rhoma Irama digunakan karena mengikuti trend. Formulasi lainnya adalah dengan mengedepankan konsistensi akan konsep kreatif. Dalam merumuskan konsep kreatif terdapat formulasi strategi iklan dalam tiga tahapan yang dimaksud dengan mengumpulkan dan mempersiapkan segala informasi pemasaran yang dibutuhkan baik mengenai informasi konsumen, produk pesaing dan selanjutnya adalah mengolah informasi yang didapat tersebut dengan menetapkan suatu positioning dan tujuan iklan dan terakhir adalah melakukan presentasi di hadapan klien guna mendapatkan persetujuan sebelum proses eksekusi dilaksanakan. 
Fauzi Ahmad, Wulan Purnama Sari: Parodi Sebagai Strategi Kreatif Iklan di Indonesia (Studi Kasus Iklan Ovo X Grab Versi Rhoma Irama

\section{Ucapan Terima Kasih}

Penulis berterima kasih kepada seluruh narasumber atau informan yakni Ibu Khania Giana selaku Sr. Copywriter dan Tegar Yudhanataru selaku Sr. Art Director dari kantor Ambilhati Agency yang bersedia bekerja sama dan memberikan waktu melakukan wawancara guna pengumpulan data. Ucapan terima kasih juga penulis berikan kepada Dosen Fakultas Ilmu Komunikasi Universitas Tarumanagara yang telah memberikan arahan, bimbingan atas terselesaikannya penelitian ini dan terakhir, kepada seluruh rekan-rekan teman diskusi di Fakultas Ilmu Komunikasi Universitas Tarumanagara.

\section{Daftar Pustaka}

Anonym, Grab, www.grab.com, diakses 24 Juni 2019.

Arens, W.W., Michael F.W., \& Christian, A. (2009). Contemporary Advertising and Integrated Marketing Communication. America (US): McGraw Hill.

Batey, Ian (2011b). Asian Branding : A Great Way To Fly. Alih bahasa, Wahab, Abdul. Jakarta: Bhuana Ilmu Populer.

Chandra, (2019). "Ovo: Penggunaan dan Cara Transaksi Jaman Now". https://www.finansialku.com/ovo/, diakses 24 Juni 2019.

Dahlan, M. Alwi. Manusia Komunikasi, Komunikasi Manusia, (Jakarta: PT. Kompas Media Nusantara, 2008).

Durianto, Darmadi, Sugiarto, Anton WW dan Hendrawan S (2003) Invasi Pasar dengan Iklan yang Efektif, PT Gramedia Pustaka, Jakarta.

Hakim, Budiman (2010b). Lanturan Tapi Relevan, Dasar-dasar Kreatif Periklanan, Yogyakarta: Galang Press.

Herdiansyah, H, (2010). Metode Penelitian Kualitatif untuk Ilmu Ilmu Sosial. Jakarta. Salemba Humanika.

Hutcheon, Linda. (2005). The Theory of Adaptation. Roudledge, New York: Taylor \& Francis Group.

Kotler, Philip., \& Kevin Keller. (2012). Manajemen Pemasaran, Edisi 13, Jilid 1, Edisi Bahasa Indonesia. Jakarta: Erlangga.

Latuconsina, Hudaya, (2010), Pengembangan Kreativitas Anak Berbakat, Jakarta: Rinek Cipta.

Miranti, Ayu. (2019). Manfaatkan Promo Grab Decacorn untuk Kebutuhan Aktivitas Harianmu, https://www.fimela.com/lifestylerelationship/read/3914971/manfaatkan-promo-grab-decacorn-untukkebutuhan-aktivitas-harianmu, diakses 24 Juni 2019.

Morissan, M.A. (2007). Periklanan; Komunikasi Pemasaran Terpadu, Jakarta: Ramdina Prakarsa.

Morissan, M.A, (2010). Periklanan: Komunikasi Pemasaran Terpadu, Jakarta: Prenada Media Group.

Munandar, S.C.U (2009). Pengembanngan Kreativitas anak Berbakat, Jakarta, PT. Rineka Cipta dan Dep. Pendidikan dan Kebudayaan.

Suhandang, Kustadi (2009b). Periklanan: Manajeemen, Kiat dan Strategi., Bandung: Nuansa.

Sukendro, G. Gregorius (2016). Kreativitas Indoneesia: Analisis Iklan Pariwisata Indonesia "Pesona Indonesia. Jakarta: Rineka Cipta. 
Vol. 3, No. 1, Juli 2019, Hal 1-8

Wulandari. (2018). "Selangkah Lebih Maju Bersama Grab Menuju Masyarakat NonTunai", https://www.grab.com/id/blog/selangkah-lebih-maju-bersama-grabmenuju-masyarakat-non-tunai/, diakses 24 Juni 2019. 